C. G. PAGE, S. J. COOPER, J. S. DEHOVITZ, D. G. OBLINSKY, K. F. BIEGASIEWICZ,

A. H. ANTROPOW, K. W. ARMBRUST, J. M. Ellis, L. G. HAMANN, E. J. HORN,

K. M. OBERG, G. D. SCHOLES, T. K. HYSTER* (PRINCETON UNIVERSITY, USA)

Quaternary Charge-Transfer Complex Enables Photoenzymatic Intermolecular Hydroalkylation of Olefins

J. Am. Chem. Soc. 2020, 143, 97-102, DOI: 10.1021/jacs.0c11462.

\section{Photoenzymatic Intermolecular Hydroalkylation of Alkenes}

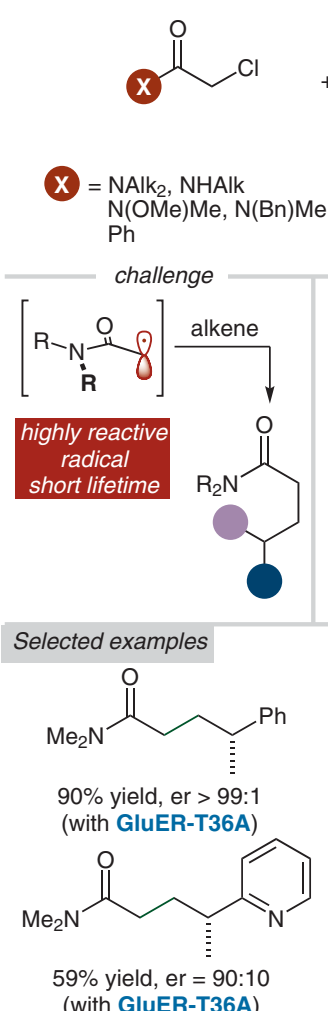

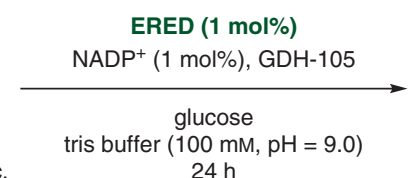

$24 \mathrm{~h}$

cyan LEDs

$$
\text { R }=\mathrm{H}, \mathrm{Alk}, \mathrm{CF}_{3}, \mathrm{CO}_{2} t-\mathrm{Bu}
$$$$
\begin{aligned}
= & (\text { het }) \mathrm{Ar}, \mathrm{OMe}, \mathrm{OAc}, \\
& \mathrm{NHCbz}
\end{aligned}
$$

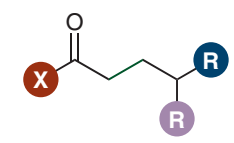

28 examples $15-99 \%$ yield er from 50:50 to $>99: 1$ 'ene'-reductases (ERED)

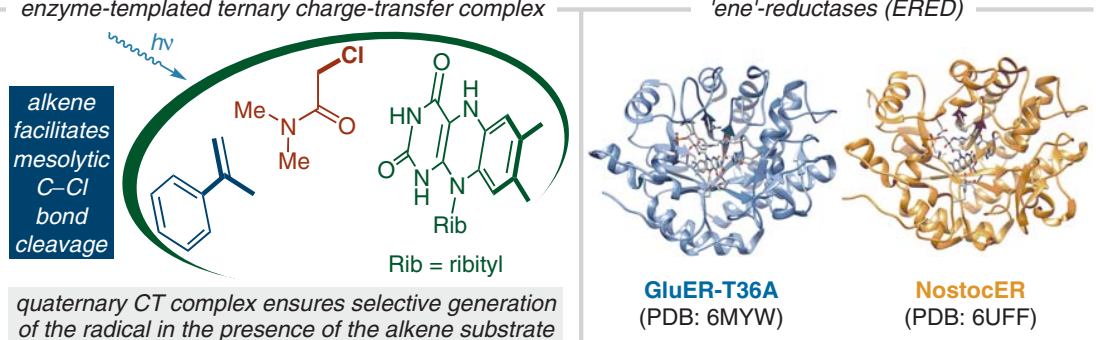

of the radical in the presence of the alkene substrate
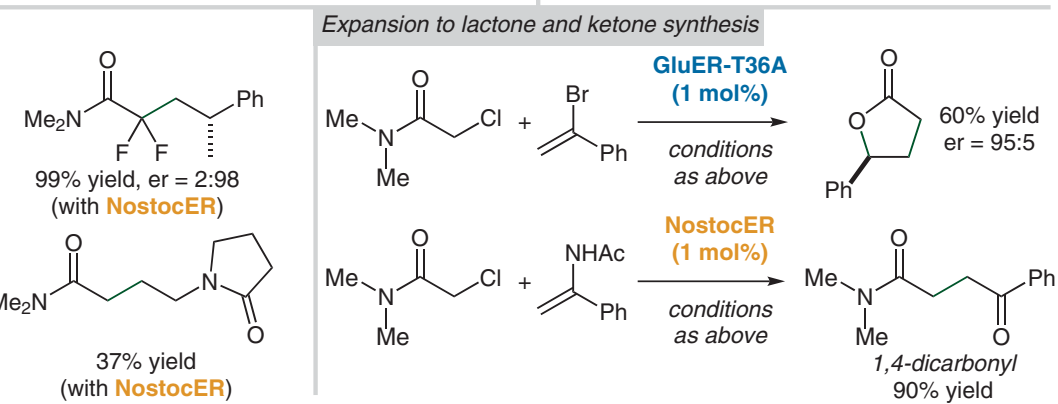

Category

Organo- and

Biocatalysis

Key words

hydroalkylation

ene-reductase

charge-transfer complex

chloro amides

alkenes

SV/
Significance: Hyster and co-workers report the application of flavin-dependent ene-reductases (EREDs) in a photoenzymatic intermolecular hydroalkylation of olefins with $\alpha$-chloro amides. A unique nonnatural mechanism, involving an enzyme-templated charge-transfer (CT) complex between the alkene, $\alpha$-chloro amide, and flavin hydroquinone cofactor, ensures that radical formation upon photoexcitation occurs exclusively when both substrates are bound within the active site. The radical-terminating hydrogen-atom transfer can be controlled by the active site of the ERED, thereby providing access to enantioenriched $\gamma$-stereogenic amides.
Comment: The authors previously discovered the formation of CT complexes when organohalides and the flavin hydroquinone cofactor within the active site of EREDs, and they applied these complexes in intramolecular C-C bond-forming reactions.

The development of the corresponding intermolecular process (see X. Huang et al. Nature 2020, 584, 69 for a related approach) is a formidable challenge, as the transient radical is prone to undergo competing hydrodehalogenation in the absence of a coupling partner. In the present study, the authors discovered that a unique quaternary CT complex gates radical formation and suppresses hydrodehalogenation, permitting an intermolecular hydroalkylation of olefins. 